\title{
Evaluating and Comparing the Usability of Web-based Course Management Systems
}

\author{
Zafer Unal \\ University of South Florida, \\ St. Petersburg, FL, USA \\ unal@mail.usf.edu
}

\author{
Asli Unal \\ Uşak University, \\ Uşak, Turkey
}

asli@zunal.com

\section{Executive Summary}

Course Management Systems (CMS) are an increasingly important part of academic systems in higher education. When choosing a Course Management System for an educational institution, the usability of the system is the key to the effectiveness and efficiency of the online courses that are to be implemented. The goal of this paper is to report the results of a comparative usability study conducted in 2008-2009 on two different course management systems: BlackBoard and Moodle.

135 students enrolled in the Fall 2008 and Spring 2009 sections of Introduction to Educational Technology participated in the study (72 and 63 respectively). At the beginning of each semester, participants were randomly divided into two groups to experience different CMSs at different times.

It can be concluded from this study that in almost every module or function comparison that was made, Moodle was favored by course participants over Blackboard with the exception of the Discussion Board module where scores were not significantly different. At the end of the study, the researchers concluded that use of Moodle in online courses can be a suitable alternative to the current CMS system (BlackBoard). In fact, now that the pilot has showed that Moodle is as effective as BlackBoard, the researchers have already shared their experiences with other faculty members and expanded their investigations by involving numerous other online courses, instructors, and students, because the product showed significant potential for further examination.

This study adds to the growing body of studies that are carried out to see if an open source CMS (Moodle) warrants consideration as an alternative to the institution's current course management system. In addition to comparing the students' feedback quantitatively, this study also tried to explain in detail what specific component / function of each CMS students found useful or better than in the other. Rather than focusing only on student satisfaction scores, this study further investigated what aspect of each module for each CMS course participants particularly liked or dis-

Material published as part of this publication, either on-line or in print, is copyrighted by the Informing Science Institute. Permission to make digital or paper copy of part or all of these works for personal or classroom use is granted without fee provided that the copies are not made or distributed for profit or commercial advantage AND that copies 1) bear this notice in full and 2) give the full citation on the first page. It is permissible to abstract these works so long as credit is given. To copy in all other cases or to republish or to post on a server or to redistribute to lists requires specific permission and payment of a fee. Contact Publisher@InformingScience.org to request redistribution permission. liked.

Keywords. course management systems, Blackboard, Moodle

\section{Introduction}

A course management system (CMS), such as Blackboard, Blackboard Vista (formerly WebCT), Desire2Learn and Moodle provides a place for learning and teaching activities to occur within a 
seamless environment (Burrell-Ihlow, 2009; Ullman \& Rabinowitz, 2004). It enables instructors and learners to post content, participate in discussions, maintain a grade book, keep a roster, track participation, and generally engage in and manage learning activities in an online environment (Heo, 2009; Lansari, Tuaishat, Al-Rawi, 2010; Rovai, Ponton, \& Baker, 2008).

In the current market space there are many commercially available course management systems from which to choose. Currently, the primary contender in this market space is Blackboard, especially when its acquisition of its main competitors WebCT and Angel course management systems are taken into consideration (eLearnity, 2005; InsideHigherEd, 2010). BlackBoard is a commercial product developed by the BlackBoard Corporation, which was founded in 1997 as a consultant to the IMS Global Learning Consortium (Tsang, Kwan, \& Fox, 2007). At present, BlackBoard has thousands of deployments over 60 countries and is available in 8 major languages (BlackBoard, 2010). It has two main product lines, namely, academic suite and commercial suite. The former supports universities and academic institutions for teaching purposes while the latter supports commercial ventures for business usage (BlackBoard, 2010).

The open source community has also been active in creating alternative course management system choices that are free of licensing costs. The main advantages of an open source course management system are the ability to modify these products and redistribute them back into the community. In the more popular open source projects, as new features become available they can be integrated into the users' existing system as needed at minimal cost. The disadvantages of open source software are a lack of dedicated support unlike proprietary systems from software manufacturers and if an organization modifies the common code base too dramatically the ability to upgrade to future releases of the software is impaired.

Open source software also requires personnel with the requisite knowledge base to implement the software, which may require additional training for current personnel. Currently the most popular open source course management system is Moodle (Chen, Wang, \& Hung, 2009; Machado \& Tao, 2007; Ramos, MacLean, Bates, Wylie, \& Brempah, 2010). Moddle was founded by Martin Dougiamas in 2001 (Moodle, 2010). It adapts a flexible modular design in which one can choose and apply among thousands of available extensions for their version of Moodle. Currently, it has more than 45 thousand deployments in over 100 countries and has been translated into 45 languages.

An institution now has the choice between many competing course management systems, both from proprietary software manufacturers and open source projects. It is not enough, however, to just pick a package based on its price or feature list. Institutions considering implementing a course management system must carefully evaluate it before putting it to use with a student population (Colace, Santo, \& Vento, 2002; Iding, Auernheimer, Crosby, \& Klemm, 2002).

The goal of this study was to carry out and report the results of a comparative usability (field) test conducted during the 2008-2009 academic year on two different course management systems, BlackBoard and Moodle. To accomplish this goal, a field test was established utilizing an alternative course management system (Moodle) to one already in use (BlackBoard) by the hosting organization. Moodle was used the first time as an alternative to the institute-wide enterprise course management system, Blackboard. 135 students enrolled in the Introduction to Educational Technology course participated in this study during two semesters. At the beginning of each semester participants were randomly divided into two groups to experience different CMSs at different times. The same experiment was repeated with another group during the next semester. During these experiments, participants were asked to share their experiences, provide their ratings and feedback on the usability test, and rate their comparisons and preferences of each course management system (response rate 100\%). There were no course withdrawals at the end of each semester. 
The study attempted to answer the following questions:

- How do participants rate their experiences with the two course management systems?

- How do participants compare the two course management systems?

- Does the use of an open source course management system (Moodle) warrant consideration as an alternative to the institution's current course management systems (BlackBoard)?

\section{Usability Testing and Course Management Systems}

The selection and adoption of a CMS by a teaching institution or a corporate training system follows the analysis of some basic parameters, usually including technical features (e.g., programming language used or required hardware infrastructure, etc.), available functions (e.g., discussion forums, integrated streaming services, etc.), supported formats (e.g., HTML, PDF, different video encoding, etc.) and learning technology standards compliance (e.g., SCORM). Such analyses are mostly system-oriented, i.e., measure a definite set of features independent from the users, and only a very limited number of comparative studies on CMS actually consider other parameters including usability concerns (Inversini, Botturi, \& Triacca, 2006; Nguyen, Chang, Chang, Jacob \& Turk, 2008). Providing web users with a usable environment can lead to significant savings and improved performances (Kibaru \& Dickson-Deane, 2010; Nielsen, 2003; Rivard \& Huff, 1988). In terms of teaching and learning, having a usable CMS means potentially reducing teacher time invested in setting up and managing the course and improving the students' learning experience - teachers and learners do not need to struggle with difficult technologies but can focus on content (Inversini et al., 2006).

Previous research suggests that online courses developed using CMS tended to suffer from a lack of attention to design (Gilbert \& Moore, 1998; Oliver, 1999; Tsang et al., 2007). Such systems gave course developers and facilitators the ability and choice to integrate many appealing options, often resulting in course designs that haphazardly integrated a variety of features that confused learners, were not instructionally sound, or did not match course objectives (Kidney \& Puckett, 2003). Concept instruction typically includes presentation of a concept definition, presentation of sample instances, and practice in classifying instances of examples and nonexamples (Tennyson $\&$ Cocchiarella, 1986). Although available features make the inclusion of presentation and guidance features common in online courses, in practice components are often weak or missing (Gilbert \& Moore, 1998; Kidney \& Puckett, 2003). Thus, given Merrill's (1997) warning that instructional strategies will teach only when they include presentation, learner guidance, and practice, failure to use provided CMS features to present and guide as well as encourage concerted practice is problematic. Confusion about the uses of available features and the mismatch of course features to learning expectations can, and often do, impede learning (Graham \& Scarborough, 2001; Kearsley, 1997; Wang, 2010).

To measure how users perform and how they perceive or think about an information system is important to the formulation of interface guidelines that are empirically justified. Research into human-computer interaction (HCI) tells us that a major design element is a technology's usability (de Lera, Fernandez, \& Valverde, 2010; Preece, Rogers, \& Sharp, 2002; Rozanski \& Haake, 2003).

Usability, a core concept of HCI, refers to interface characteristics that are easy to use, learn, and remember, and that are pleasant to use and generate the least errors (Nielsen, 1993). The concept of usability has been defined by a number of researchers, but a complete definition is difficult to achieve outside the domain within which it is considered (Petersen, 2007; Simbulan, 2007). To properly define usability as it has evolved during the past few years, three original approaches have to be included. Jakob Nielsen defined the concept of web usability by stating that making web pages simple to navigate and intuitively organized helps the users find the information they 
are looking for with ease (Nielsen, 1994). Nokelainen (2006) expanded Nielsen's definition to include pedagogical usability, suggesting that usability involves techniques for ensuring a trouble-free interaction with the software while pedagogical usability aims at supporting the learning process. A further refinement creates the term "learnability" which is highly recommended in evaluations of e-learning environments (Kakasevski, Mihajlov, Arsenovski \& Chungurski, 2008; Neal, n.d.). In the world of e-learning, the definition of learnability is expanded to include the ability of users to effectively learn and retain the skills and knowledge, as well as learn how to use the system (Neal, n.d.).

Information technology adoption and diffusion has been studied in great detail in recent years by researchers in the information systems area. Adoption is defined as the decision to accept or invest in a technology. Information technology adoption can be studied at two levels: the first is at the organizational level and the other is at the individual level. If the unit of analysis is an individual, the emphasis is on the acceptance of the technology. The Technology Acceptance Model (TAM) proposed by Davis (1989) has explained acceptance of information technology. TAM states that an individual's adoption of information technology is dependent on their perceived ease of use and perceived usefulness of the technology. This model has been used and tested, and at times modified, to study the adoption of a number of different technologies in the past decade (Lucas \& Spitler, 1999; Venkatesh \& Davis, 1996). As a theoretical framework, this study used the technology acceptance model (TAM) which has been successfully applied in examining adoption behavior of various information systems (e.g. Jackson, Chow, \& Leitch, 1997; Venkatesh \& Davis, 2000), in various organizational contexts (e.g. Agarwal \& Prasad, 1999; Hsu \& Chiu, 2004; Igbaria, Zinatelli, Cragg, \& Cavaye, 1997; Venkatesh \& Davis, 2000). Previous studies have found TAM to have a relatively simple structure but comparable explanatory power to more sophisticated models, such as the theory of reasoned action and the theory of planned behavior (Davis, Bagozzi, \& Warshaw, 1989; Mathieson, 1991; Taylor \& Todd, 1995). The main purpose of TAM is to predict the intention to utilize information systems by measuring users' perceptions of the system's usefulness and ease of use. Moreover, TAM proposes that the effects of external variables on usage intention are mediated by these perceptions. Therefore, by utilizing TAM as a theoretical framework, the study was able to investigate the impact of external variables on user acceptance of digital libraries.

Usability and user acceptance tests are usually conducted with the help of a group of participants representing the intended user community, who are asked to perform certain tasks under the observation of controllers who analyze their actions. At the end of the observation, users are often invited to make general comments or give suggestions about how the system can be improved. Typical of usability tests is the think aloud technique, in which users are asked to "think aloud" about what they are doing while performing their task, so that their observers can understand their actions better (Dray \& Siegel, 2004; Kantner, Sova, \& Rosenbaum, 2003; Rowley, 1994). A limitation of this type of test is that it usually focuses on first-time and short-time usage and has a limited coverage of the range of interface features or tasks (Brush, Ames, \& Davis, 2004; Shneiderman, 1998). Therefore, it is difficult to verify how a system will perform over a certain period of regular use. Because of this, usability tests are often integrated with other evaluation techniques, including field tests (Kakasevski et al., 2008).

Field tests can be considered to be a special kind of usability test (note that usability tests are usually conducted in controlled settings, while field tests are conducted in natural settings). During field tests new products are put to work in realistic environments for a fixed trial period. Special examples of field tests are beta versions of software: test versions distributed to users in order to verify them. This type of usability test provides extensive usage and data is collected over a period of time through focus group interviews or surveys (Kakasevski et al., 2008; Preece et al., 2002). 


\section{Methodology}

Two course management systems were compared during this study: BlackBoard 7.0 (updated to 8.0 during study) (BlackBoard, 2010) and Moodle 1.9 (Moodle, 2010). These CMSs were used to support an Educational Technology course offered during Fall 2008 and Spring 2009 semesters in a Southeastern university. The university already had BlackBoard in place and the course has been taught online only via BlackBoard.

For this study, Moodle was installed on the university's servers located in the campus IT building and administered by academic technologies personnel. The instructor of the courses was experienced in both systems previously.

EME2040- Introduction to Educational Technology is an educational technology course that introduces classroom applications of educational technologies to its students. It is one of the three required courses for students majoring in education in the State University System. The course topics and activities included the following weekly format (Table 1).

\begin{tabular}{|l|l|l|}
\hline \multicolumn{2}{|c|}{ Table 1. Course Activities } \\
\hline$\#$ & Course Activities & Time Spent \\
\hline 1 & Educational Software Evaluation & 1 week \\
\hline 2 & Educational Website Evaluation & 1 week \\
\hline 3 & Creating an Educational Game via PowerPoint & 1 week \\
\hline 4 & Creating an Excel GradeBook & 1 week \\
\hline 5 & Creating a WebQuest & 3 weeks \\
\hline 6 & Creating a Technology Integrated Lesson Plan & 1 week \\
\hline 7 & Copyright Quiz & 1 week \\
\hline 8 & Online Discussion on Technology \& Parental Involvement & 1 week \\
\hline 9 & Creating a Teacher Website & 4 week \\
\hline 10 & Online Discussion / Chat & Ongoing \\
\hline
\end{tabular}

One hundred thirty five students enrolled in the Fall 2008 and Spring 2009 section of Introduction to Educational Technology participated in the study (72 and 63 respectively). At the beginning of each semester, participants were randomly divided into two groups to experience different CMSs at different times.

The course instructor copied the BlackBoard version of the course to Moodle, transferring the same features (modules) (Table 2). In the meantime the researchers created an online survey and interview forms and obtained approval from the Institutional Review Board prior to the course. 


\begin{tabular}{|l|l|}
\hline \multicolumn{2}{|c|}{ Table 2. Features Used In Each Course Management Systems } \\
\hline BlackBoard & Moodle \\
\hline Announcements & News Forum \\
\hline Course Documents & Lessons \\
\hline Assignment Manager & Assignment/Activity \\
\hline Discussion Board & Discussion Forum \\
\hline Collaboration Tools & Collaboration Tools \\
\hline Communications & Participants \\
\hline My Grades & My Grades \\
\hline
\end{tabular}

At the beginning of each semester, each group used the instructors' generic course web site for two weeks. The course web site was constructed using HTML editor tools and provided students with access to course announcements and course material. It had no specialized features central to web-based learning tools such as assignment submission, quizzes or communication tools. After the first two-week period in the term each group was asked to use their assigned CMS system, Blackboard and Moodle, for six weeks and use the other one for the remaining six weeks (Table $3)$.

\begin{tabular}{|l|l|l|l|}
\hline \multicolumn{4}{|c|}{ Table 3. Student Experiences } \\
\hline Procedure & Time & Fall08 & Spring09 \\
\hline Course Website HTML & First 2 weeks & 72 students & 63 students \\
\hline BlackBoard, then Moodle & $6+6$ weeks & Group 1:36 students & Group 1: 31 students \\
\hline Moodle, then BlackBoard & $6+6$ weeks & Group 2: 36 students & Group 2:32 students \\
\hline
\end{tabular}

At the end of each semester, the researchers provided a link to an online survey to collect participants' experiences with the two CMS systems. The survey conducted after the completion of the course included multiple choice questions, scaled-answer questions, and open-ended questions and consisted of three sections: demographic questions, students' comparison of two CMS systems regarding usability (ease of use, efficiency, effectiveness, memorability, satisfaction), and overall satisfaction with the course. The survey also allowed participants to provide additional comments or suggestions on any issues that were not addressed in the previous sections of the survey.

\section{Results and Discussions}

In this section, findings of the study will be listed to present a comparison of the two systems used during the study. In order to provide consistency, the CMS systems (BlackBoard and Moodle) will be listed and results will be provided alphabetically (Blackboard first and Moodle second). 
During this experiment, participants were asked to rate their experiences and feedback on each of these components of the two course management systems. The results that follow were received for each module and overall.

\section{Course Format / Layout}

Perhaps the biggest difference between Blackboard and Moodle is the available course format / layout. Blackboard has one instructor layout and it has a compartmentalized presentation. The layout is based on a navigation bar on the left. It uses different sections for each tool and lets instructors add folders, files, or direct content into each section (announcements, documents, assignments, resources, etc.). The navigation area can be modified by activating/de-activating each section. However, the compartmentalized layout is standard and cannot be changed (Figure 1).

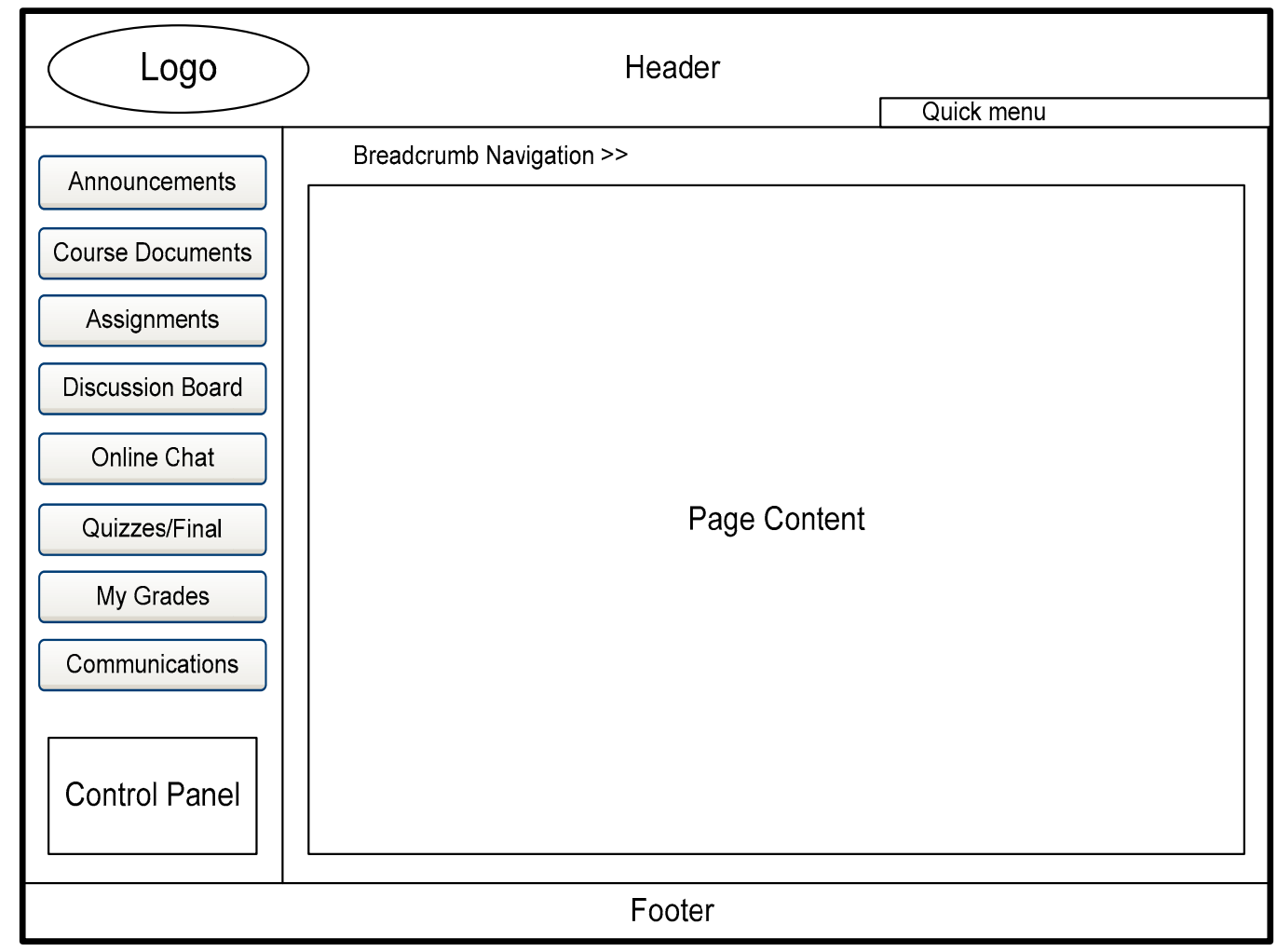

Figure 1. BlackBoard CMS System Course Layout

In Moodle, instructors are able to choose one of the three different formats: weekly, topics, or social. The weekly format is organized week by week, with a clear start date and a finish date. Each week consists of activities. The topics format is similar to the weekly format, except that each "week" is called a topic. The social format is oriented around one main forum, the social forum, which appears listed on the main page. It is useful for situations that are more freeform.

The layout used during this experiment was "weekly." The default layout of Moodle includes a broad column in the center and two narrow side columns. Most of the course materials and activities are located in the broad central column, organized by topics or weeks. This content column is divided into large squares or "sections" and can include several kinds of activities, resources, and links to choose for users (Figure 2). 


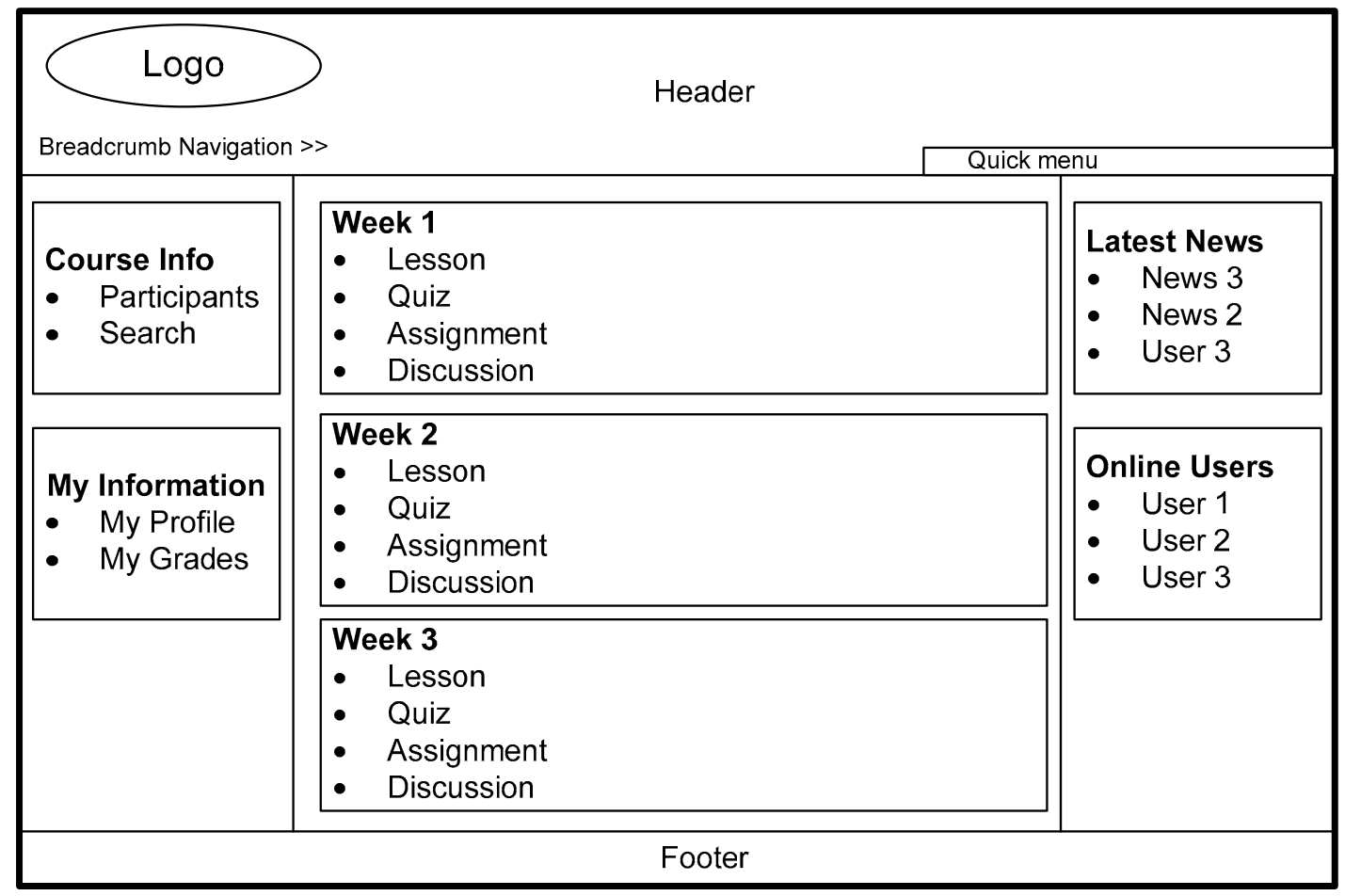

Figure 2. Moodle CMS System Course Layout

In the comparison of the two systems for course format / layout, the study found that users favored Moodle over BlackBoard (Table 4).

\begin{tabular}{|l|c|c|c|c|}
\hline \multicolumn{2}{|c|}{ Table 4. Student Satisfaction Scores on Course Layout for BlackBoard and Moodle } \\
\hline & \multicolumn{2}{|c|}{ BlackBoard } & \multicolumn{2}{c|}{ Moodle } \\
\hline & Mean & SD & Mean & SD \\
\hline Fall 2008 $(\mathrm{n}=72)$ & 3.1 & .79 & 4.0 & .86 \\
\hline Spring 09 $(\mathrm{n}=63)$ & 3.3 & .86 & 3.9 & 1.1 \\
\hline All Participants(n=135) & 3.1 & .91 & 3.9 & .69 \\
\hline
\end{tabular}

Rating Scale 5 - Highest and 1 - Lowest score

When participants were asked, "What reasons would you give to support your choice?" responses were themed as follows (Table 5). 
Table 5. Participants' Responses on CMS Layouts

\begin{tabular}{|l|l|}
\hline I prefer BlackBoard, because & I prefer Moodle, because \\
\hline$\bullet \quad$ I have previous experience with & $\bullet \quad$ Weekly blocks where everything listed helped a lot. \\
Blackboard, made it easy. & $\bullet \begin{array}{l}\text { I did not need to visit entire website every time I } \\
\text { logged in. }\end{array}$ \\
& $\begin{array}{l}\text { It was very easy to navigate. Everything was very } \\
\text { clear. }\end{array}$ \\
& $\begin{array}{l}\text { The fact that Moodle had each week lessons and an } \\
\text { activity mapped out was very helpful. }\end{array}$ \\
& $\begin{array}{l}\text { I knew exactly where to go for my class rather than } \\
\text { doing a dig up first. }\end{array}$ \\
\hline
\end{tabular}

\section{Announcements / News}

One of the most used modules in online courses is the Announcement (in BlackBoard) or News (in Moodle) module. Even though they are named differently, the purpose of these modules is the same. It is to help the instructor to keep course participants updated regarding important information about the course.

In BlackBoard, the main - homepage - section is filled with this module. By default, this is the first page students reach when they log into BlackBoard. Using the control panel, the instructor has full access to post new Announcements or delete/modify the old ones. It can be configured that the post can stay in the Announcement page permanently or disappear after a certain time.

In Moodle, even though the idea is the same, implementation is a little bit different. The News forum module is used for general announcements. This forum is automatically created for each course and for the front page of the Moodle site. By default, it is placed in the top of the center section and only teachers and administrators may add posts or reply to posts. The default settings force every enrolled person to be subscribed to the News forum. When using this module, instructors in both CMS systems can attach files to their posts and also select the option of immediate emails of the post to be sent to course participants.

While in BlackBoard students can respond to the announcement as a reply to the instructor via email, in Moodle, students can reply via email and post to the forum. Instructors can choose the option of letting participants respond directly from the course page for the course news posting; in BlackBoard participants are not allowed to respond directly from the course website. In the comparison of the two systems for course announcements, the study found that users favored Moodle over BlackBoard (Table 6) and responses were themed as follows (Table 7).

\begin{tabular}{|l|c|c|c|c|}
\hline \multicolumn{1}{|c|}{ Table 6. Student Satisfaction Scores on Announcement Module for BlackBoard and Moodle } \\
\hline & \multicolumn{2}{|c|}{ BlackBoard } & \multicolumn{2}{c|}{ Moodle } \\
& Mean & SD & Mean & SD \\
\hline Fall 2008 $(\mathrm{n}=72)$ & 3.6 & 1.2 & 3.9 & .72 \\
\hline Spring 09 $(\mathrm{n}=63)$ & 3.6 & .94 & 3.7 & .95 \\
\hline All Participants(n=135) & 3.6 & 1.1 & 3.8 & .56 \\
\hline
\end{tabular}

Rating Scale 5 - Highest and 1 - Lowest score 


\begin{tabular}{|l|l|}
\hline \multicolumn{2}{|c|}{ Table 7. Participants' Responses on Announcement/News Modules } \\
\hline I prefer BlackBoard, because & I prefer Moodle, because \\
\hline$\bullet \quad \begin{array}{l}\text { I received Announcements via } \\
\text { BlackBoard and email. }\end{array}$ & $\begin{array}{l}\text { I was able view announcement in the body email, I } \\
\text { did not have to login to BlackBoard to view mes- } \\
\text { sage. }\end{array}$ \\
& $\begin{array}{l}\text { I was able to reply to the announcement via email or } \\
\text { forum. }\end{array}$ \\
\hline
\end{tabular}

\section{Lessons / Course Documents}

One of the major components of an online course is the delivery of the course content. The course content was delivered via text, image, and video files that included sets of instructions related to accomplishing course objectives.

In BlackBoard, the "Course Documents" module was used to provide course content and instruction. The instruction materials were delivered as multiple documents for students to study that included text, images, and lesson videos. Course participants accessed these materials directly when they were made available weekly.

In Moodle, the "Lesson" module was used for delivering course content. A lesson in Moodle is a series of interactive pages that require a choice for course participants before the next page appears. In other words, each page normally ends with a question and a number of possible answers. Depending on the choice of answer course participants either progressed to the next page or were taken back to a previous page. During the course, lessons were only scored to provide access to next page and scores were not added into the course grade since the feature was not available in BlackBoard (Figure 3).

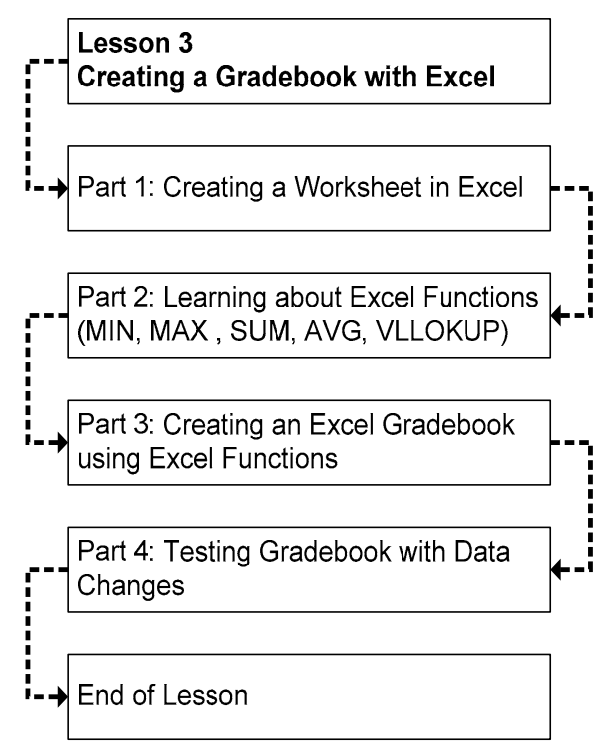

A BlackBoard Lesson

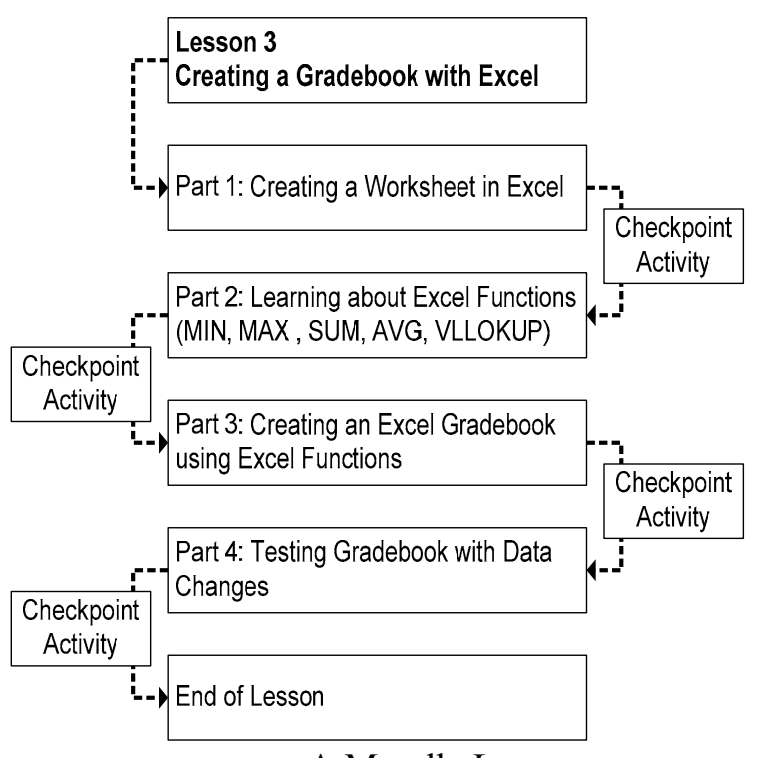

A Moodle Lesson

Figure 3. Comparison of Lesson Module in BlackBoard and Moodle 
In the comparison of the two systems for course lessons/course documents, the study found that users favored Moodle over BlackBoard (Table 8) and responses were themed as follows (Table 9).

\begin{tabular}{|l|c|c|c|c|}
\hline \multicolumn{1}{|c|}{ Table 8. Student Satisfaction Scores on Lesson/Course Documents for BlackBoard / Moodle } \\
\hline & \multicolumn{2}{|c|}{ BlackBoard } & \multicolumn{2}{c|}{ Moodle } \\
& Mean & SD & Mean & SD \\
\hline Fall 2008 (n=72) & 2.9 & .98 & 3.9 & 1.2 \\
\hline Spring 09 (n=63) & 3.0 & .74 & 3.8 & .94 \\
\hline All Participants(n=135) & 2.9 & .87 & 3.8 & 1.1 \\
\hline
\end{tabular}

Rating Scale 5 - Highest and 1 - Lowest score

Table 9. Participants' Responses on Lesson/Course Documents Modules

\begin{tabular}{l|l} 
I prefer BlackBoard, because & I prefer Moodle, because
\end{tabular}

- A questionnaire was not required to view the next section of the lesson,

- Learned material better because lessons on Moodle were separated into sections and each section provided related questionnaire.

- Spent more time on a lesson in BlackBoard than Moodle

- Questionnaires on lessons made sure that lessons were read before jumping to next section. This made sure that I followed the lesson and practices.

- Lessons in Moodle were more interactive and engaging than BlackBoard.

- Lessons were prepared more creatively.

\section{Discussion Board}

Discussion is a core feature of courseware management tools, and it is seen as a basic component of web-based courses (Brown, 2000) since it provides the main vehicle for communication between participants.

In BlackBoard, the Discussion Board is made up of forums that may appear anywhere in the course but are also all centrally located in the Discussion Board tool. Participants choose a discussion board to enter, click on the name of the board to be able to add new topics or reply to others. In Moodle, the thread is created automatically when the instructor creates the forum. Students can reply to current thread and to each other's postings. Everything will be displayed on a single page. When a student selects the forum from the course page, it will automatically open the discussion board and all replies will be visible at once in nested format. Moodle also provided an opportunity for instructor to hide messages posted previously in a discussion before a student respond with their reply.

In the comparison of the two systems for Discussion Board, the study found that users favored Moodle and BlackBoard almost equally (Tables 10 and 11). 


\begin{tabular}{|l|c|c|c|c|}
\hline \multicolumn{2}{|c|}{ Table 10. Student Satisfaction Scores on Discussion Board Module for BlackBoard / Moodle } \\
\hline & \multicolumn{2}{|c|}{ BlackBoard } & \multicolumn{2}{c|}{ Moodle } \\
\hline & Mean & SD & Mean & SD \\
\hline Fall 2008 $(n=72)$ & 3.8 & .98 & 3.8 & 1.2 \\
\hline Spring 09 $(n=63)$ & 3.7 & .74 & 3.8 & .94 \\
\hline All Participants(n=135) & 3.7 & .87 & 3.8 & 1.1 \\
\hline
\end{tabular}

Rating Scale 5 - Highest and 1 - Lowest score

Table 11. Participants' Responses on Discussion Board Modules

\begin{tabular}{|c|c|}
\hline I prefer BlackBoard, because & I prefer Moodle, because \\
\hline $\begin{array}{l}\text { - In BlackBoard, in addition to } \\
\text { how many messages total, it } \\
\text { shows how many new (un- } \\
\text { read) messages per forum. It } \\
\text { was helpful to have how many } \\
\text { messages are new / unread for } \\
\text { each forum. In addition, } \\
\text { BlackBoard allowed marking } \\
\text { "read" messages as } \\
\text { "new/unread". } \\
\text { BlackBoard allowed editing a } \\
\text { post anytime. Moodle allowed } \\
\text { editing the post for } 30 \text { minutes } \\
\text { after the post made. } \\
\text { A spell-checker was available } \\
\text { in BlackBoard }\end{array}$ & $\begin{array}{l}\text { Discussions were much easier and relaxing in Moodle } \\
\text { because I did not worry about what is posted already } \\
\text { before I sent mine. Even when replying to a question as } \\
\text { one of the last people in class, I did not have to scan all } \\
\text { the messages and come up with something original to } \\
\text { say because I was not able to see what is posted already } \\
\text { before I post mine. } \\
\text { Locating the discussion forum for each week was easy } \\
\text { task while BlackBoard required multiple clicks. } \\
\text { It was easier to read topics/threats instead of just indi- } \\
\text { vidual posts. Selecting the forum and then selecting the } \\
\text { topic provided all messages posted under the topic au- } \\
\text { tomatically. In Blackboard, there were numerous steps } \\
\text { to take to read messages together posted under the same } \\
\text { topic. } \\
\text { Moodle discussion board provided WYSIWYG editor } \\
\text { where participants were able copy paste from other files }\end{array}$ \\
\hline
\end{tabular}

\section{Assignment Submission}

The course required participants to upload assignment files into the course management system.

The Assignment Manager in Blackboard provides users with an area where course assignments can be posted, related files uploaded with comments, and grades published. To submit an assignment in BlackBoard, participants access the online Assignment Activity page, upload their assignment file(s), check that the file(s) are correct, and submit the assignment. Once the assignment has been submitted, participants are able to make changes (e.g., add another file or delete the file and upload a revised version) until the due date.

In the comparison of the two systems for Assignment Submission, the study found that users favored Moodle over BlackBoard (Table 12 \& 13). 
Table 12. Student Satisfaction Scores on Assignment Module for BlackBoard and Moodle

\begin{tabular}{|l|c|c|c|c|}
\hline & \multicolumn{2}{|c|}{ BlackBoard } & \multicolumn{2}{c|}{ Moodle } \\
\hline & Mean & SD & Mean & SD \\
\hline Fall 2008 $(\mathrm{n}=72)$ & 3.4 & 1.3 & 3.9 & .65 \\
\hline Spring 09 $(\mathrm{n}=63)$ & 3.3 & .91 & 3.8 & .96 \\
\hline All Participants(n=135) & 3.4 & .94 & 3.8 & .80 \\
\hline
\end{tabular}

Note: Rating Scale 5 - Highest and 1 - Lowest score

Table 13. Participants' Responses on Assignment Modules

\begin{tabular}{l|l} 
I prefer BlackBoard, because & I prefer Moodle, because
\end{tabular}

- In BlackBoard, in addition to receiving a score and short comment, the assignments were returned as a file which included instructor's review right on the same file.

- Assignment re-submission for revised file(s) was allowed before the assignment due date. In BlackBoard, submissions were final.

- When uploading an assignment that required multiple file submission (lesson plan \& PowerPoint); it was possible to upload files separately. BlackBoard lets you make one submission only as a whole package.

\section{Group Work, Collaboration, and Communication}

Many educators recognize the importance of learning within a group, taking advantage of telecommunication technologies, and generally support the idea that collaborative learning through computer-mediated communication can positively affect students' educational experience (Graham \& Scarborough, 2001). Teamwork and collaboration are essential elements in a virtual setting due to technological advances and business globalization (Johnson, Suriya, Yoon, Berrett, \& La Fleur, 2002). Therefore, one of the most important features of a course management system is the available modules and factions that allow course participants work together as a small or large group. Through CMS, participants are able to share documents, chat, send emails, and work together in synchronous and asynchronous environments.

Both BlackBoard and Moodle provided elements required for collaboration, group work, and communication between course participants. Both CMSs allowed the instructor to create groups and assign students to each group manually. Through the communication tools, participants were able to email to their peers, their groups, the whole class, or only the instructor. Group members were able to share documents with each other, and they were also able to work on a single document together through a wiki module which kept a history of the changes. Both systems provided a chat area for communication among users or groups, supported unlimited simultaneous group discussions, and allowed instructors to moderate chats and suspend students from the chat rooms if needed. Archived logs of all chat rooms are available in both.

Even though it was not a critical element for this course, Moodle provided an extra feature. It offered participants an opportunity to upload their profile pictures. When posting on a discussion board, replying a message, sending an email through Moodle, chatting, or any other place in the CMS that participants' names are placed, the profile picture was also found automatically. This provided a great opportunity for students to recognize each other easily; furthermore, they gener- 
ated interest and contributed to users' involvement. The profile picture linked to a profile page that contained information about the person that other users could see, including the description of the person, name, location, email address. This information was available only if the participants permitted access.

In the comparison of the two systems for Collaboration and Communication tools, the study found that users favored Moodle over BlackBoard (Tables 14 and 15).

\begin{tabular}{|l|c|c|c|c|}
\hline \multicolumn{2}{|c|}{ Table 14. Student Satisfaction Scores on Collaboration and Communication Tools } \\
\hline & \multicolumn{2}{|c|}{ BlackBoard } & \multicolumn{2}{c|}{ Moodle } \\
\hline & Mean & SD & Mean & SD \\
\hline Fall 2008 $(\mathrm{n}=72)$ & 3.4 & .87 & 3.7 & .89 \\
\hline Spring 09 $(\mathrm{n}=63)$ & 3.4 & .95 & 3.8 & 1.0 \\
\hline All Participants(n=135) & 3.4 & .91 & 3.7 & 1.2 \\
\hline
\end{tabular}

Rating Scale 5 - Highest and 1 - Lowest score

Table 15. Responses on Group Work, Communication and Collaboration Tools

\begin{tabular}{|l|l|}
\hline I prefer BlackBoard, because & I prefer Moodle, because
\end{tabular}

- Moodle automatically subscribed my email to discussions and group work communications. I ended up unsubscribing my email from most of the sections. In BlackBoard, I started with no subscription as default and was able to subscribe myself for the ones I chose.

- Whiteboard section where we met online and draw our ideas on WebQuest project was very useful for our project.
- Student-student interaction is necessary for the class especially for WebQuest, and Technology integrated lesson plans. Working as a group on these projects using chat and group work area in Moodle helped a lot.

- "As much as I hated to see mine, seeing the other people's pictures was nice. Sometimes you have a lot of people in the class and you do not remember their names but every time you see that (referring participant pictures) it helps you remember, make a connection who that person was, so in some ways it was more helpful than having a class like this (referring classroom session) and it help me to know that it was a real class."

\section{Gradebook}

The online grade book allows instructors to add an online or offline assignment or task to the course so that course participants receive a score for completing each assignment/task. Naturally, in a gradebook, an instructor can post, update, or remove grades for all students and import or export the GradeBook to an external application while a course participant can only view their own grade for each task. 
During this study, both BlackBoard and Moodle provided the basic gradebook functions mentioned above. In each CMS, the gradebook allowed instructors to create a course grading scale that can employ percents, letter grades, or pass/fail metrics. They both provided grade weighting, which is the practice of counting critical assessments more highly than less critical assessments based on how they correspond to the relative importance and the number of learning objectives being assessed. Both systems also provided categorization and statistical reports. In the comparison of the two systems for the Gradebook tool, the study found that users favored Moodle over BlackBoard (Tables 16 and 17).

\begin{tabular}{|l|c|c|c|c|}
\hline \multicolumn{4}{|c|}{ Table 16. Student Satisfaction Scores on Gradebook Tool } \\
\hline & \multicolumn{2}{|c|}{ BlackBoard } & \multicolumn{2}{c|}{ Moodle } \\
\hline & Mean & SD & Mean & SD \\
\hline Fall 2008 $(\mathrm{n}=72)$ & 3.7 & .94 & 3.9 & .60 \\
\hline Spring 09 $(\mathrm{n}=63)$ & 3.5 & .86 & 3.8 & .96 \\
\hline All Participants(n=135) & 3.6 & .70 & 3.8 & .81 \\
\hline
\end{tabular}

Rating Scale 5 - Highest and 1 - Lowest score

Table 17. Participants' Responses on Gradebook

\begin{tabular}{|c|c|}
\hline I prefer BlackBoard, because & I prefer Moodle, because \\
\hline - No specific response & $\begin{array}{l}\text { - Received automatic email when an assignment } \\
\text { is graded in both Moodle and BlackBoard. } \\
\text { However, BlackBoard forced me to login to } \\
\text { BlackBoard to see my grade while Moodle in- } \\
\text { cluded it within the email. }\end{array}$ \\
\hline
\end{tabular}

\section{Conclusion}

From a student's perspective, course management systems are a step above a classroom website. Information sharing is no longer static; these systems utilize tools that allow both synchronous (different place but same time) and asynchronous (different place, different time) interaction. They have the most important task: addressing the needs of the ultimate end user - the learner. Each course management system available currently has key features that allow students to be actively involved in their courses, including downloading and uploading files, participating in chat and discussion boards, taking assessments, viewing grades, and contacting teachers and classmates.

When choosing a CMS for an educational institution, the usability of the system is the key to the effectiveness and efficiency of the online courses that are to be implemented. One of the most important aspects of an effective CMS is the usability for both instructors and learners. The effectiveness of the course will help the learners achieve the specific goals of the course. The ease of navigation through the course will help the learners achieve their goals. If the course is not effective or efficient, then it will affect the students' learning. 
The goal of this study was to report the results of a comparative usability study conducted in 2008-2009 on two different course management systems, BlackBoard and Moodle. It can be concluded from this study that in almost every module or function comparison that was made, Moodle was favored by course participants over BlackBoard with the exception of the Discussion Board module where scores were not significantly different.

At the end of the study, the researchers concluded that use of Moodle in online courses can be a suitable alternative to the current CMS system (BlackBoard). In fact, now that the pilot has showed that Moodle is as effective as BlackBoard, the researchers have already shared their experiences with other faculty members and expanded their investigations by involving numerous other online courses, instructors, and students, because the product showed significant potential for further examination.

This study adds to the growing body of studies that are carried out as the initial attempt to research to see if an open source CMS (Moodle) warrants consideration as an alternative to the institution's current course management system. In addition to comparing the students' feedback quantitatively, this study also tried to explain in detail what specific component / function of each CMS students found useful or better than the other. Rather than focusing only on student satisfaction scores, this study further investigated what aspect of each module for each CMS course participants particularly liked or disliked.

This study is an example of a pilot study on students' first time experiences with Moodle during their Introduction to Educational Technology Course and reports the results of a comparative usability (field) test. This study can be used as a guide to be easily replicated to help educators to test their own findings, at their own institutions by exploring additional concepts, implementing supplementary models to the conceptual framework, expanding the population of interest, analyzing additional educational settings, and using other research designs.

Even though the focus of this study was to investigate and compare the usability of two course management systems to see if an open source course management system (Moodle) warrants a consideration as an alternative to the institution's current course management system (BlackBoard), there are other factors that can influence such decision. Operational factors include reliability, external support, flexibility in design and functions, and features of the CMS, stability and security and strategic factors include ease of adaptation, stability of the platform.

The total cost of ownership is another important factor to consider. It is a fact that commercial systems require high fees, which may be prohibitive for educators and institutions working with limited budgets. Some universities and colleges are beginning to be able to afford only the basic versions of these commercial systems and that can threaten to diminish the educational experiences of students. This is forcing smaller universities to consider cheaper CMS alternatives, especially during times of such a volatile economy and shrinking budgets.

This study has certain limitations. The study has small sample size, includes only one course, and focuses only on students' perspectives of use of Moodle. Further studies are recommended for educators to conduct their own tests of the alternatives or other studies focusing on pedagogical value, financial concerns, support issues, assessment criteria for accreditation, integration with the information technology services, and long-term viability are recommended. 


\section{References}

Agarwal, R., \& Prasad, J. (1999). Are individual differences germane to the acceptance of new information technologies? Decision Sciences, 30(2), 361-391.

BlackBoard. (2010). BlackBoard Incorporation. Retrieved May 25, 2010 from www.blackboard.com

Brown, B. L. (2000). Web-based training. ERIC Clearinghouse on Adult, Career, and Vocational Education. Retrieved on May 3, 2010 from http://www.ericacve.org/docgen.asp?tbl=digests\&ID=103

Brush, A. J. B, Ames, M., \& Davis, J. (2004). A comparison of synchronous remote and local usability studies for an expert interface. Proceedings of Computer Human Interaction 2004, 1179-1182

Burrell-Ihlow, M. (2009). An investigation of teaching and learning: Using course management software (CMS) in a typically face to face course. International Journal on E-Learning, 8(1), 5-16. Chesapeake, VA: AACE.

Chen, D-T., Wang, Y-M., \& Hung, D. (2009). A journey on refining rules for online discussion: Implications for the design of learning management systems. Journal of Interactive Learning Research, 20(2), 157-173. Chesapeake, VA: AACE.

Colace, F., Santo, M. D., \& Vento, M. (2002). Evaluating on-line learning platforms: A case study. Paper presented at the 36th Hawaii International Conference on System Sciences, Big Island, Hawaii.

Davis, F. D. (1989). Perceived usefulness, perceived ease of use, and user acceptance of information technology. MIS Quarterly, 13(3), 319-340.

Davis, F. D., Bagozzi, R. P., \& Warshaw, P. R. (1989). User acceptance of computer technology: A comparison of two theoretical models. Management Science, 35(8), 982-1003.

De Lera, E., Fernandez, C., \& Valverde, L. (2010). The emotional gap in virtual online environments. In Z. Abas et al. (Eds.), Proceedings of Global Learn Asia Pacific 2010 (pp. 67-70). AACE.

Dray, S., \& Siegel, D. (2004). Remote possibilities? International usability testing at a distance. Interactions, 11(2), 10-17.

ELearnity. (2005). Blackboard acquires WebCT, Retrieved May 25, 2010 from http://www.elearnity.com/EKCLoad.htm?load=ByKey/DWIN6H6CTB

Gilbert, L., \& Moore, D. (1998). Building interactivity in Web courses: Tools for social and instructional interaction. Educational Technology, 38, 29-35.

Graham, M., \& Scarborough, H. (2001). Enhancing the learning environment for distance education students. Distance Education, 22(2), 232-244.

Heo, M. (2009). Design considerations for today's online learners: A study of personalized, relationshipbased social awareness information. International Journal on E-Learning, 8(3), 293-311. Chesapeake, VA: AACE.

Hsu, M. H., \& Chiu, C. M. (2004). Internet self-efficacy and electronic service acceptance. Decision Support Systems, 38(3), 369-381.

Iding, M. K., Auernheimer, B., Crosby, M. E., \& Klemm, E. B. (2002). Guidelines for designing evaluations of web based instructional materials. Paper presented at the 36th Hawaii International Conference on System Sciences, Big Island, Hawaii.

Igbaria, M., Zinatelli, N., Cragg, P., \& Cavaye, A. (1997). Personal computing acceptance factors in small firms: A structural equation model. MIS Quarterly, 21(3), 279-305.

InsideHigherEd. (2010). Blackboard buys Angel. Inside higher education organization, Retrieved May 25, 2010 from http://www.insidehighered.com/news/2009/05/07/bb

Inversini, A., Botturi, L., \& Triacca, L. (2006). Evaluating LMS usability for enhanced elearning experience. Paper presented at the EDMEDIA Conference, Orlando, Florida. 
Jackson, C. M., Chow, S., \& Leitch, R. A. (1997). Toward an understanding of the behavioral intention to use an information system. Decision Sciences, 28(2), 357-389.

Johnson, S. D., Suriya, C., Yoon, S. W., Berrett, J. V., \& La Fleur, J. (2002). Team development and group processes of virtual learning teams. Computers and Education, 39(4), 379-393.

Kakasevski, G., Mihajlov, M., Arsenovski, S., \& Chungurski S. (2008). Evaluating usability in learning management system Moodle. Proceedings of the 30th International Conference ITI Cavtat/Dubrovnik, Croatia, June 23-26, 2008, p.613-618

Kantner, L., Sova, H. D., \& Rosenbaum, S. (2003). Alternative methods for field usability research. Proceedings of Special Interest Group for Design of Communication Conference, 2003, 68-72

Kearsley, G. (1997). A guide to online education. Retrieved May 1, 2010, from http://gwis.circ.gwu.edu/etl/online.html

Kibaru, F., \& Dickson-Deane, C. (2010). Model for training usability evaluators of e-learning. In J. Sanchez \& K. Zhang (Eds.), Proceedings of World Conference on E-Learning in Corporate, Government, Healthcare, and Higher Education 2010 (pp. 517-522). Chesapeake, VA: AACE.

Kidney, G., \& Puckett, E. (2003). Rediscovering the first principles through online learning. Quarterly Review of Distance Education, 4, 203-212.

Lansari, A., Tubaishat, A., \& Al-Rawi, A. (2010). Using a learning management system to foster independent learning in an outcome-based university: A gulf perspective. Proceedings of Issues in Informing Science and Information Technology (pp. 73-87). Retrieved from http://iisit.org/Vol7/IISITv7p073087Lansari733.pdf

Lucas, H. C., \& Spitler, V. K. (1999). Technology use and performance: A field study of broker workstations. Decision Sciences, 30(2), 291-311.

Machado, M., \& Tao, E. (2007). Blackboard vs. Moodle: Comparing user experience of learning management systems. Paper presented at the 37th ASEE/IEEE Frontiers in Education Conference, Milwaukee, WI.

Mathieson, K. (1991). Predicting user intentions: Comparing the technology acceptance model with the theory of planned behavior. Information Systems Research, 2(3), 173-191.

Merrill, M. (1997). Instructional strategies that teach. Computer Based Training Solutions, 1-11.

Moodle. (2010). Moodle organization. Retrieved May 25, 2010 from www.moodle.org

Neal, L. (n.d.). Q\&A with Don Norman. eLearn Magazine. Retrieved December 21, 2010 from http://www.elearnmag.org/subpage.cfm? section=articles\&article=16-1

Nielsen, J. (1993). Usability engineering. Massachusetts: Academic Press

Nielsen, J. (1994). Heuristic evaluation. In J. Nielsen \& R. L. Mack (Eds.), Usability inspection methods (pp. 25-62). New York: John Wiley \& Sons.

Nielsen, J. (2003). Usability 101: Introduction to usability. Retrieved May 25, 2010 from http://www.useit.com/alertbox/20030825.html

Nokelainen, P. (2006). An empirical assessment of pedagogical usability criteria for digital learning material with elementary school students. Educational Technology \& Society, 9(2), 178-197

Nguyen, T., Chang, V., Chang, E., Jacob, C., \& Turk, A. (2008). A contingent method for usability evaluation of web-based learning systems. In K. McFerrin et al. (Eds.), Proceedings of Society for Information Technology \& Teacher Education International Conference 2008 (pp. 579-585). Chesapeake, VA: AACE.

Oliver, R. (1999). Exploring strategies for online teaching and learning. Distance Education, 20(2), 240254. 
Petersen, D. (2007). Usability theory, practice and evaluation for learning objects. In K. Harman \& A. Koohang (Eds.), Learning objects: Applications, implications, \& future directions (pp.337-370). Santa Rosa, CA: Informing Science Press.

Preece, J., Rogers, Y., \& Sharp, H. (2002). Interaction design: Beyond human-computer interaction. Hoboken, NJ: John Wiley \& Sons.

Ramos, K., MacLean, A., Bates, P., Wylie, P., \& Brempah, A. (2010). Using Moodle lessons for the development of an e-learning programme in women's heath. In J. Sanchez \& K. Zhang (Eds.), Proceedings of World Conference on E-Learning in Corporate, Government, Healthcare, and Higher Education 2010 (pp. 764-769). Chesapeake, VA: AACE.

Rivard, S., \& Huff, S. (1988). Factors of success for end-user computing. Communications of the ACM, $31(5), 552-561$.

Rovai, A. P., Ponton, M. K., \& Baker, J. D. (2008). Distance learning in higher education. A programmatic approach to planning, design, instruction, evaluation, and accreditation. New York, NY: Teachers College Press.

Rowley, D. E. (1994). Usability testing in the field: Bringing the laboratory to the user. Proceedings of the SIGCHI Conference on Human Factors in Computing Systems: Celebrating Interdependence, 252257.

Rozanski, E. P., \& Haake, A. R. (2003). Curriculum and content: The many facets of HCI. Paper presented at the 4th Conference on Information Technology Curriculum on Information Technology Education, Lafayette, IN.

Simbulan, M. S. (2007). Learning objects' user interface. In K. Harman \& A. Koohang (Eds.), Learning objects: Applications, implications, \& future directions. (pp. 259-336). Santa Rosa, CA: Informing Science Press.

Shneiderman, B. (1998). Designing the user interface (3rd ed.). Pearson Education.

Taylor, S., \& Todd, P. A. (1995). Assessing IT usage: The role of prior experience. MIS Quarterly, 19(4), 561-570.

Tennyson, R. D., \& Cocchiarella, M. J. (1986). An empirically based instructional design theory for teaching concepts. Review of Educational Research, 56(1), 40-71.

Tsang, P., Kwan, R., \& Fox, R. (2007). Enhancing learning through technology. World Scientific Publishing Co.

Ullman, C., \& Rabinowitz, M. (2004). Course management systems and the reinvention of instruction. THE Journal. Retrieved May 25, 2010 from www.thejournal.com/articles/17014

Venkatesh, V., \& Davis. F. D. (1996). A model of the antecedents of perceived ease of use: Development and test. Decision Sciences, 27(3), 451-481.

Venkatesh, V., \& Davis, F. D. (2000). A theoretical extension of the technology acceptance model: Four longitudinal field studies. Management Science, 46(2), 186-204.

Wang, H. (2010). Towards a real virtual classroom. Proceedings of World Conference on Educational Multimedia, Hypermedia and Telecommunications 2010 (pp. 1123-1129). Chesapeake, VA: AACE. 


\section{Biographies}

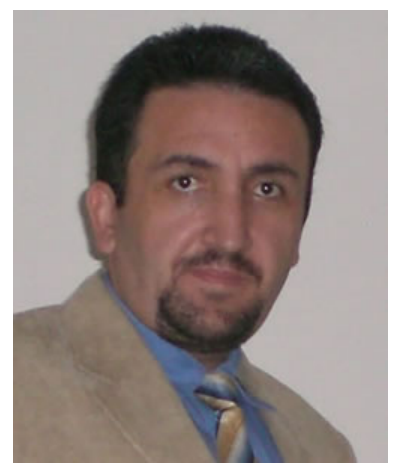

Zafer Unal is an Assistant Professor of Childhood Education, serving as assessment coordinator for the College of Education, coordinating the college wide assessment system at University of South Florida, St. Petersburg. Dr. Unal earned his doctorate degree in Elementary Education from Florida State University. His areas of research are using technology as an instructional tool, distance education, and assessment of teacher candidate learning and online portfolios. He teaches undergraduate and graduate courses.

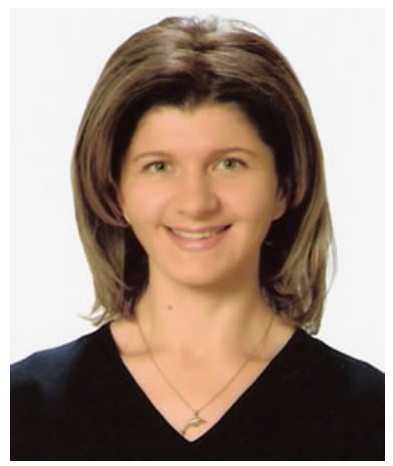

Asli Unal is an Assistant Professor of Elementary Education, teaching undergraduate and graduate courses for the College of Education at Usak University, Turkey. Dr. Unal earned her doctorate degree in Elementary Education from Florida State University. Her areas of research are parental involvement, educational technology and classroom management. 